Check for updates

Cite this: Mater. Adv., 2021, 2, 4009

Received 6th May 2021, Accepted 15th May 2021

DOI: $10.1039 / \mathrm{d} 1 \mathrm{ma} 00414$

rsc.li/materials-advances

\section{Multi-purpose heterogeneous catalyst material from an amorphous cobalt metal-organic framework $\dagger$}

\author{
Kefeng Ping, $\ddagger^{a}$ Mahboob Alam, $\ddagger^{a}$ Sean Ray Kahnert, $\S^{a}$ Rohit Bhadoria, ${ }^{a}$ Arvo Mere, ${ }^{b}$ \\ Valdek Mikli, ${ }^{\text {b }}$ Maike Käärik, ${ }^{c}$ Jaan Aruväli, ${ }^{d}$ Päärn Paiste, ${ }^{d}$ Arvo Kikas, ${ }^{e}$ \\ Vambola Kisand, ${ }^{e}$ Ivar Järving, ${ }^{a}$ Jaan Leis, ${ }^{c}$ Nadežda Kongi (D) *c and \\ Pavel Starkov (iD *a
}

\begin{abstract}
Sustainable technologies rely on the development of universal catalyst materials. While a lot of the attention has been given to improving the performance of one single catalyst material for one specific application, there is still a need to find ways to develop catalysts that can simultaneously be utilized for several chemo- and electrocatalytic processes. In this work, we have surveyed a series of novel, cobaltbased catalyst materials derived from an amorphous MOF in an array of diverged applications. Specifically, we have focused on organic transformations such as oxidative of alkylarenes and benzylic homocoupling reactions as well as several electrocatalytic processes, which directly relate to energy conversion and storage devices, such as oxygen reduction (ORR), oxygen evolution (OER) and hydrogen evolution (HER) reactions. We have observed that only one material, TAL-2-900, delivered the optimal solution. The stability and recyclability of this unique multifunctional material has been examined.
\end{abstract}

\section{Introduction}

The notion of $\mathrm{M}-\mathrm{N}-\mathrm{C}$ catalysts, where $\mathrm{M}$ is typically $\mathrm{Fe}, \mathrm{Co}, \mathrm{Mn}$ or $\mathrm{Ni}$, is often reserved for the catalysts developed for applications in energy conversion and storage devices. ${ }^{1-3}$ However, recent reports have also emphasized the potential of this type of materials in facilitating heterogeneous organic transformations. ${ }^{4-6}$

There is an accountable divergence in the ways that the $\mathrm{M}-\mathrm{N}-\mathrm{C}$ materials are prepared, and they depend on the ultimate application prerogative. ${ }^{1-12}$ When used in the electrochemical settings, the underlying materials are typically acid-etched to make sure that the additional influence of related nanoparticles (metal and/or that of metal oxides, carbides, nitrides, sulfides and phosphides) deposited directly at the surface of the catalyst

\footnotetext{
${ }^{a}$ Department of Chemistry and Biotechnology, Tallinn University of Technology, Tallinn 12618, Estonia. E-mail: pavel.starkov@taltech.ee

${ }^{b}$ Department of Materials and Environmental Technology, Tallinn University of Technology, Tallinn 19086, Estonia

${ }^{c}$ Institute of Chemistry, University of Tartu, Tartu 50411, Estonia. E-mail: nadezda.kongi@ut.ee

${ }^{d}$ Institute of Ecology and Earth Sciences, University of Tartu, Tartu 50411, Estonia ${ }^{e}$ Institute of Physics, University of Tartu, Tartu 50411, Estonia

$\dagger$ Electronic supplementary information (ESI) available. See DOI: 10.1039/ d1ma00414j

¥ These authors contributed equally.

$\S$ Present address: Institute of Organic Chemistry, Clausthal University of Technology, Clausthal-Zellerfeld 38678, Germany.
}

is eliminated. In heterogeneous catalysis applications, however, the contribution of these species to the overall chemical reactivity while being well acknowledged and often relied upon - is not readily distinguished from the instances of single-atom catalysis $^{9,10}$ and the role that nanocrystals protected by graphitic carbon layers might play.

Metal-organic frameworks (MOFs) are one of the most attractive building blocks for the formation of active $\mathrm{M}-\mathrm{N}-\mathrm{C}$ materials. ${ }^{12}$ Whereas only a handful of crystalline MOFs can directly be used as electrocatalysts, ${ }^{13-15}$ a vast majority of MOFs still require an additional carbonization step to allow for increased stability and conductivity as well as to introduce a variety of catalytically active species $\left(\mathrm{M}-\mathrm{N}_{x}\right) \cdot{ }^{12}$ During this process, additional doping with heteroatoms and metals ${ }^{7,8}$ or the use of alternative supports ${ }^{16,17}$ is often advantageous.

While crystalline MOFs are widely used for carbonization, ${ }^{7-9}$ their innate crystallinity may not always be a critical factor to achieve high catalytic activities (aside from contributing to the topology). All the catalyst materials reported to date are based on monometallic (e.g. MIL-101, ZIF-67, MOF-74-Zn, Prussian blue analogues) ${ }^{11}$ and mixed ligand/mixed metal (e.g. the MIL101/ZIF-67 composite ${ }^{18}$ and ZnCo-MOFs ${ }^{19}$ ) MOFs are highly crystalline. During the pyrolysis, however, MOFs undergo drastic molecular rearrangements; hence, amorphous MOFs can be used as the precursors. ${ }^{20,21}$ To this end, we recently assessed iron-based catalysts derived from polycrystalline 
metal-organic framework precursors (TAL-1-900, TAL-6-900, TAL-7-900), ${ }^{22,23}$ which were based on carbon-rich ${ }^{24}$ organic linkers. Even the slightest variations around the benzimidazole core have led to alterations in the performance of the materials as bifunctional oxygen electrocatalysts ${ }^{22}$ and in heterogeneous catalysis. $^{23}$

Herein, we report a unique amorphous cobalt-based MOF-derived multifunctional material, which acts as an efficient trifunctional electrocatalyst $^{25,26}$ and as a robust heterogeneous catalyst.

\section{Results and discussion}

\subsection{Morphological and physical characterizations}

We prepared a series of catalysts from an amorphous metalorganic framework precursor TAL-2 by carbonizing it at different temperatures (Fig. 1). Importantly, we have treated these carbonized materials with $0.5 \mathrm{M} \mathrm{HNO}_{3}$ to remove the traces of cobalt( 0 ) and cobalt oxides from the surface of the materials. Regardless of this treatment, the final porous $\mathrm{M}-\mathrm{N}-\mathrm{C}$ materials still contained cobalt $(0)$ nanoparticles, which were protected by the graphitic layers as is evident from the high resolution transmission electron microscopy (HRTEM; Fig. 1B-D and Fig. S1, S2, ESI $\dagger$ ) micrographs. Increasing the temperature of carbonization did not lead to a substantial change in the $\mathrm{N}_{2}$ adsorption/desorption isotherms or the distribution of pore sizes, which effectively remained in the $3-4 \mathrm{~nm}$ range (Fig. 1E and F). However, as is seen in the powder X-ray diffraction (PXRD; Fig. 1G) patterns and the microwave plasma-atomic emission spectroscopy (MP-AES; Table S1, ESI $\dagger$ ) datasets, the graphitic carbon and cobalt(0) content was significantly higher in the samples that have been treated at 900 and $1000{ }^{\circ} \mathrm{C}$. The X-ray photoelectron spectroscopy (XPS) data indicated that carbonization at higher temperatures both lowered the nitrogen content and altered the distribution of nitrogen species at the surface (Fig. S3 and Tables S1-S5, ESI $\dagger$ ).

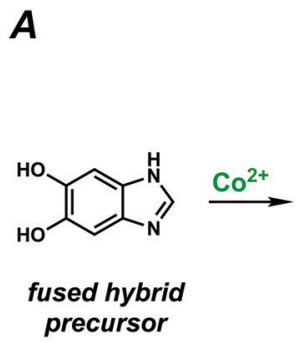<smiles>COc1cc2c(cc1OC)C1(CO)CCCCN21</smiles>

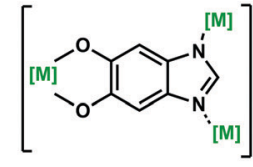

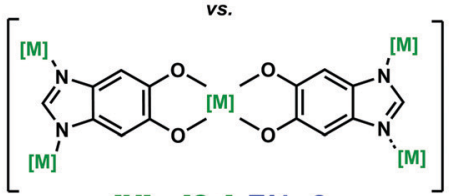

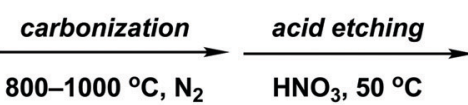

TAL-2-900

TAL-2-1000

surveyed active catalysts
B

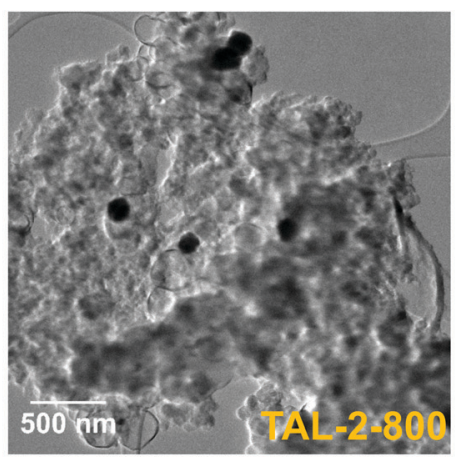

$\boldsymbol{E}$

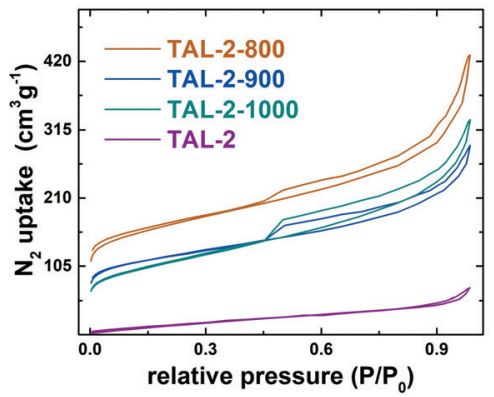

C

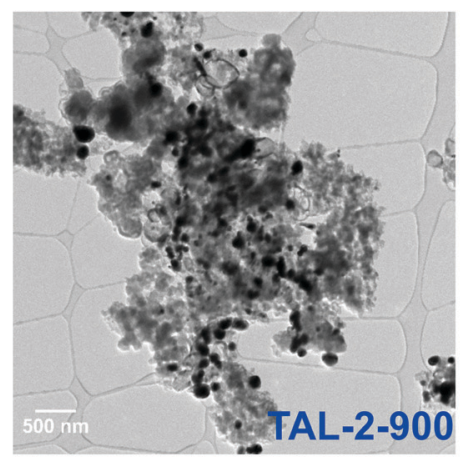

$\boldsymbol{F}$

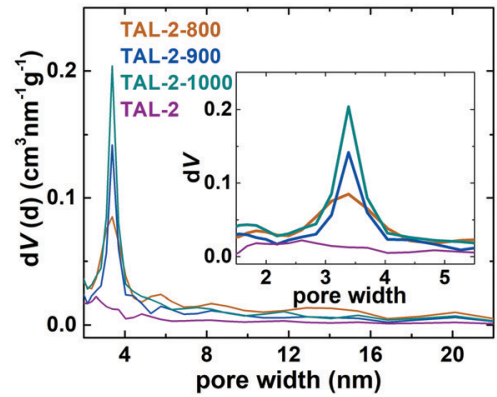

D

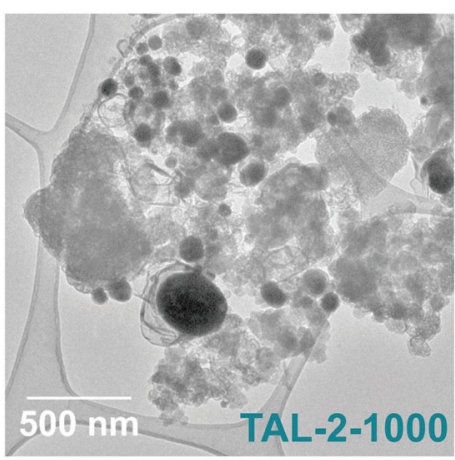

G

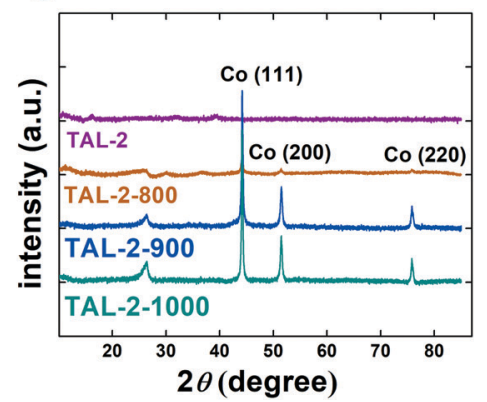

Fig. 1 (A) Preparation of TAL-2 derived catalysts materials. HRTEM micrographs of (B) TAL-2-800, (C) TAL-2-900 and (D) TAL-2-1000 catalysts. Physical characterization of the materials by (E) $\mathrm{N}_{2}$ uptake, and (F) pore size distribution and (G) PXRD patterns. 


\subsection{Oxidative organic transformations}

The de novo $\mathrm{Co}-\mathrm{N}-\mathrm{C}$ catalysts were screened against oxidative transformations with tert-butyl peroxide (TBHP) as terminal oxidant at a considerably low catalyst loadings, namely, that of $5 \mathrm{mg} \mathrm{mmol}{ }^{-1}$. While TBHP-driven oxidations of arylmethanes have been reported to be catalyzed by $\mathrm{Fe}-\mathrm{N}-\mathrm{C}$ materials effectively, ${ }^{23,27-29}$ the cobalt corresponding $\mathrm{Co}-\mathrm{N}-\mathrm{C}$ catalysts were not. ${ }^{30}$ Typically, Co-N-C catalysts are used for reduction reactions (nitroarenes, ${ }^{31,32} \mathrm{~N}$-heterocycles, ${ }^{33}$ and hydrocarbons ${ }^{34}$ ), reductive aminations ${ }^{35}$ and alkylations, ${ }^{36,37}$ while the oxidative esterification of benzyl alcohols were done under dioxygen. ${ }^{38-40}$

Overall, the cobalt materials outperformed the three previously reported related Fe-N-C systems (TAL-1-900, TAL-6-900, TAL-7-900), ${ }^{22,23}$ and importantly, they sustained their activity over a larger number of cycles (Fig. 2A and B; Tables S6 and S7, ESI $\dagger$ ). TAL-2-900 and TAL-2-1000 were more active because they contained metallic Co nanoparticles, which were protected by graphitic carbon layers, as confirmed by PXRD and HRTEM.

Interestingly, TAL-2-900 was a more robust catalyst for converting toluene to benzoic acid, while TAL-2-1000 was better at oxidizing diphenylmethane to benzophenone. This indicates that small differences in the active sites (e.g. the total content of pyridinic nitrogen) at the surface of the catalyst play an important role in catalyst stability. A further set of substrates was subjected to oxidation (Fig. 2C). Addition of acetic acid slightly improved the yields in the cases where polymethylated arenes were converted to the corresponding carboxylic acids.

\subsection{Benzylic homocoupling}

Knowing that radical pathways were involved in oxidative transformation reactions, has encouraged us to extend the use of TAL-2-900 as a heterogeneous catalyst for carbon-carbon bond forming reactions via activation at the benzylic positions. While $\mathrm{M}-\mathrm{N}-\mathrm{C}$ materials are widely explored in oxidative and reductive processes, ${ }^{4-6}$ there is only a handful of examples of their use in other organic transformations. For instance, Zhang et al. developed an oxidative coupling between primary and secondary alcohols. ${ }^{41}$ This reaction was shown to proceed via formation of intermediary aldehydes and ketones, respectively, which undergo aldol condensation. A reductive $\mathrm{C}-\mathrm{H}$ alkylation of quinolines by aldehydes using cobalt-based catalysts was also demonstrated. ${ }^{42,43}$

We were interested to see whether the $\mathrm{M}-\mathrm{N}-\mathrm{C}$ catalysts could be compatible with organometallic reagents; hence, we explored $\mathrm{C}\left(\mathrm{sp}^{3}\right)-\mathrm{C}\left(\mathrm{sp}^{3}\right)$ homocoupling reaction of benzyl bromides in the presence of a Grignard reagent. This reaction traditionally requires stoichiometric metallic lithium, ${ }^{44}$ magnesium, ${ }^{45}$ copper $^{46}$ or nickel. ${ }^{47}$ Recently, a rhodium-catalyzed
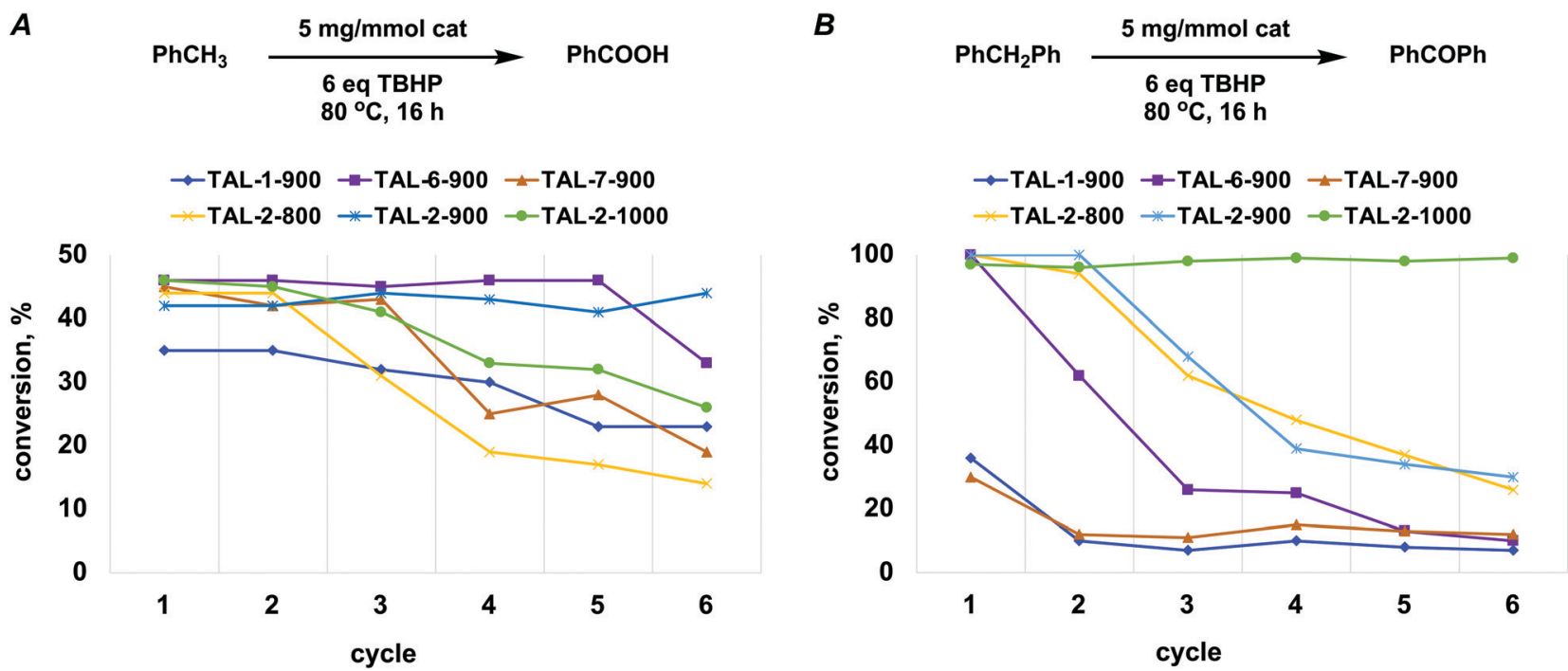

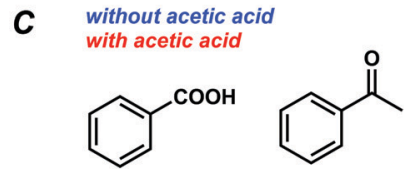

$93 \%$ from $\mathrm{BnOH}^{\mathrm{a}}$ $81 \%$ from $\mathrm{BnCOOH}$ from para-xylene

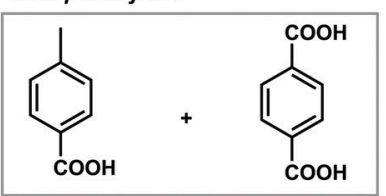

$42 \%+3 \%^{a}$ $47 \%+8 \%^{b}$
$47 \%$ from meta-xylene

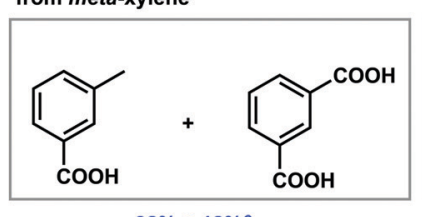

$32 \%+18 \%^{a}$ $45 \%+24 \%^{b}$ from mesitylene

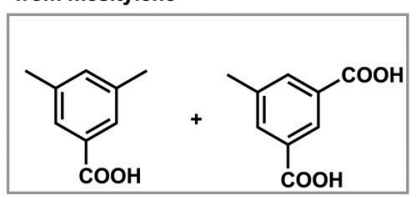

$16 \%+37 \%^{a}$ $20 \%+47 \%^{b}$

${ }^{a}$ Reaction conditions: substrate (1.0 equiv), TBHP ( 6 equiv per $\mathrm{CH}_{3}$ group), TAL-2-900 ( $\left.5 \mathrm{mg} / \mathrm{mmol}\right)$, neat, $80^{\circ} \mathrm{C}, 24 \mathrm{~h} .{ }^{b} \mathrm{Additional}$ AcOH (1 equiv per $\mathrm{CH}{ }_{3}$ group)

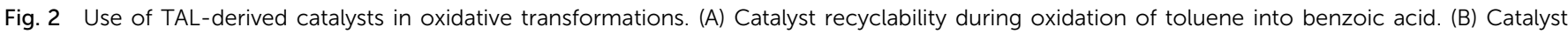

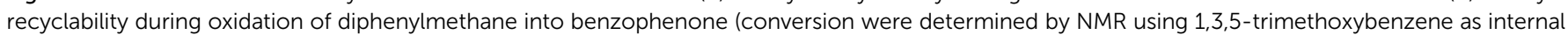
standard). (C) Substrate scope for TAL-2-900-catalyzed oxidations (isolated yields). 

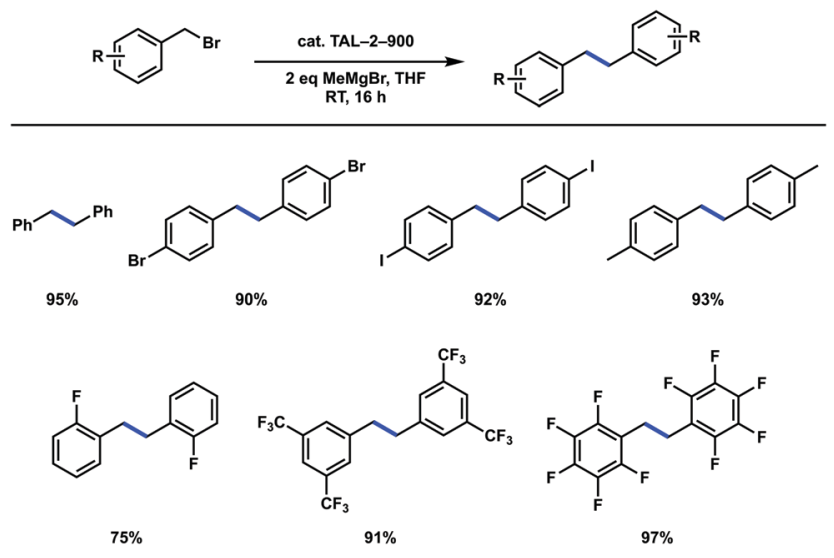

a Reaction conditions: substrate (1.0 equiv), MeMgBr (2.0 equiv), TAL-2-900 (5 mg/mmol), THF, RT, $16 \mathrm{~h}$

Scheme 1 TAL-2-900 catalyzed $\mathrm{C}\left(\mathrm{sp}^{3}\right)-\mathrm{C}\left(\mathrm{sp}^{3}\right)$ homocoupling reactions ${ }^{a}$.

version employing dimethylzinc was demonstrated, ${ }^{48}$ and several photocatalyzed conditions were developed. ${ }^{49,50}$ Gratifyingly, we observed the desired homocoupling products with cobalt based catalyst TAL-2-900 but not the iron version (TAL-1-900) (Scheme 1). The reactions were carried out using methylmagnesium bromide at ambient temperature to give corresponding bibenzyls in good to excellent yields, while aryliodides and bromides were also well tolerated. After standard aqueous workup, the spent catalyst had a significantly reduced activity. Specifically, on the next cycle, the isolated yield of homocoupled product has dropped from $93 \%$ to $38 \%$. Alternatively, the THF solution containing the product was removed by syringe under anhydrous conditions and the reaction vessel was recharged with THF, benzyl bromide and MeMgBr. This modification gave the desired product with an improved yield on the second run $(93 \%)$.

\subsection{Electrocatalytic transformations}

After having identified the most promising catalyst for the organic transformations, we wished to screen the TAL-2 catalyst series as trifunctional electrocatalyst materials across oxygen reduction (ORR), oxygen evolution (OER) and hydrogen evolution (HER) reactions (Fig. 3). Potentially, these datasets should give insights into whether there is a link between the performance of the individual catalysts across electrocatalytic and chemocatalytic interconversions..$^{51,52}$ Out of the three catalysts, TAL-2-900, once again, showed a superior activity profiles in all of the electrocatalytic reactions.

To learn the effect of different carbonization temperatures on electrocatalytic ORR performance, TAL-2 based catalysts were tested by rotating disc electrode (RDE) and rotating ringdisc electrode (RRDE) techniques in $0.1 \mathrm{M} \mathrm{KOH}$ electrolyte. Oxygen reduction polarization curves (Fig. 3A) confirmed that TAL-2 based catalyst carbonized at $900{ }^{\circ} \mathrm{C}$ had the highest ORR electrocatalytic activity with an onset potential $\left(E_{\text {on }}\right)$ of $1.00 \mathrm{~V}$, a half-wave potential $\left(E_{1 / 2}\right)$ of $0.85 \mathrm{~V}$ and a diffusion-limiting current density of $-5.78 \mathrm{~mA} \mathrm{~cm}{ }^{-2}$. The kinetic parameters of TAL-2-900 were on par with the ones obtained for commercial $\mathrm{Pt} / \mathrm{C}$ catalyst $\left(E_{\mathrm{on}}=1.01 \mathrm{~V} ; E_{1 / 2}=0.86 ; j_{\mathrm{d}}=-6.16 \mathrm{~mA} \mathrm{~cm}^{-2}\right)$ and other promising non-noble metal ORR catalysts (Table S9, ESI $\dagger$ ). Despite the fact that BET surface area of TAL-2-900 $\left(421 \mathrm{~m}^{2} \mathrm{~g}^{-1}\right)$ is lower than that obtained for TAL-2-800 $\left(589 \mathrm{~m}^{2} \mathrm{~g}^{-1}\right.$ ) (Table S11, ESI $\dagger$ ), the superior ORR performance of TAL-2-900 indicates higher density of electrochemically accessible active sites for ORR.

To shed light on the enhancement of the ORR activity, electrochemically active surface area (ECSA) of TAL-2 derived catalysts was estimated by collecting the electrochemical double-layer capacitance $\left(C_{\mathrm{dl}}\right)$ from CV curves (Table S10, ESI $\dagger$ ). The ECSA values have decreased for the samples that were obtained by increasing the carbonization temperatures. Hence, the superior electrocatalytic activity of the TAL-2-900 sample may be explained by a higher amount of ORR active sites, specifically in the form of cobalt $(0)$ nanoparticles.

The Koutecky-Levich (K-L) plots were constructed using data derived from RDE (Fig. S4, ESI $\dagger$ ) and the calculated number of electrons transferred per oxygen molecule $n$ was in all the cases approximately four. RRDE studies confirmed that oxygen reduction proceeds via a two-step $2 \times 2 \mathrm{H}_{2} \mathrm{O}_{2}$ mechanism (Fig. S5B and C, ESI $\dagger$ ). The Tafel plot analysis demonstrated that the TAL-2-900 material had the highest slope value $\left(-76 \mathrm{mV}\right.$ decade $\left.^{-1}\right)$ against all the other samples that were surveyed in this study (Fig. 3B). Similarly to Pt/C, this means that the rate determining step for ORR is the first electron transfer step, whereby $\mathrm{O}_{2(\mathrm{ads})}$ is reduced to $\mathrm{O}_{2(\mathrm{ads})}{ }^{-}$. A continuous potential cycling in the range between 0.6 and $1.0 \mathrm{~V}$ was used to assess the long-term stability of TAL-2-900, with $E_{1 / 2}$ shifting only by $20 \mathrm{mV}$ after 5,000 cycles (Fig. 3C). The RDE studies have confirmed that TAL-2-900 was a highly stable active ORR electrocatalyst in $0.1 \mathrm{M} \mathrm{KOH}$.

The electrocatalytic activity towards ORR of the TAL-2-900 material has also been tested under acidic conditions $(0.5 \mathrm{M}$ $\mathrm{H}_{2} \mathrm{SO}_{4}$; Fig. S7, ESI $\dagger$ ). As in the case of alkaline media, TAL-2900 has shown higher onset and half-wave potentials $(0.82 \mathrm{~V}$ and $0.73 \mathrm{~V} v s$. RHE) than those for TAL-2-800 and TAL-2-1000. Notably, TAL-2-900 remained stable after 5000 cycles with $E_{1 / 2}$ having decreased only by $20 \mathrm{mV}$ (Fig. S7D, ESI $\dagger$ ).

The OER performance of the TAL-2 derived catalysts was assessed and $\mathrm{i} R$-corrected OER polarization curves are shown in Fig. 3D. The benchmark current density of $10 \mathrm{~mA} \mathrm{~cm}{ }^{-2}$ was achieved at $1.60 \mathrm{~V}$ for TAL-2-900 material, which is superior to that of ruthenium oxide $(1.69 \mathrm{~V})$. The Tafel slopes obtained for the OER electrocatalytic activity among the series, confirm that TAL-2-900 functions similarly to the $\mathrm{RuO}_{2}$ systems. Under the long-term OER operation, this catalyst material is stable (Fig. 3F). The overall oxygen bifunctional electroactivity $(\Delta E)$ value for TAL-2-900 is $0.75 \mathrm{~V}$, which makes it much lower than the rest of the $\mathrm{M}-\mathrm{N}-\mathrm{C}$ samples, whilst haven been screened at the similar loadings (Table S10, ESI $\dagger$ ).

The electrocatalytic HER activity of the best performing catalyst was compared with the commercial $\mathrm{Pt} / \mathrm{C}$ in $1 \mathrm{M} \mathrm{KOH}$ (Fig. 3G and $\mathrm{H}$ ) at the current density of $-10 \mathrm{~mA} \mathrm{~cm}{ }^{-2}$. Under these conditions, the overpotential with TAL-2-900 as a catalyst was achieved at $-264 \mathrm{mV} v$ s. RHE with a low Tafel slope value of $115 \mathrm{mV} \mathrm{dec}{ }^{-1}$. The HER overpotential values $\eta$ for TAL-2-800 

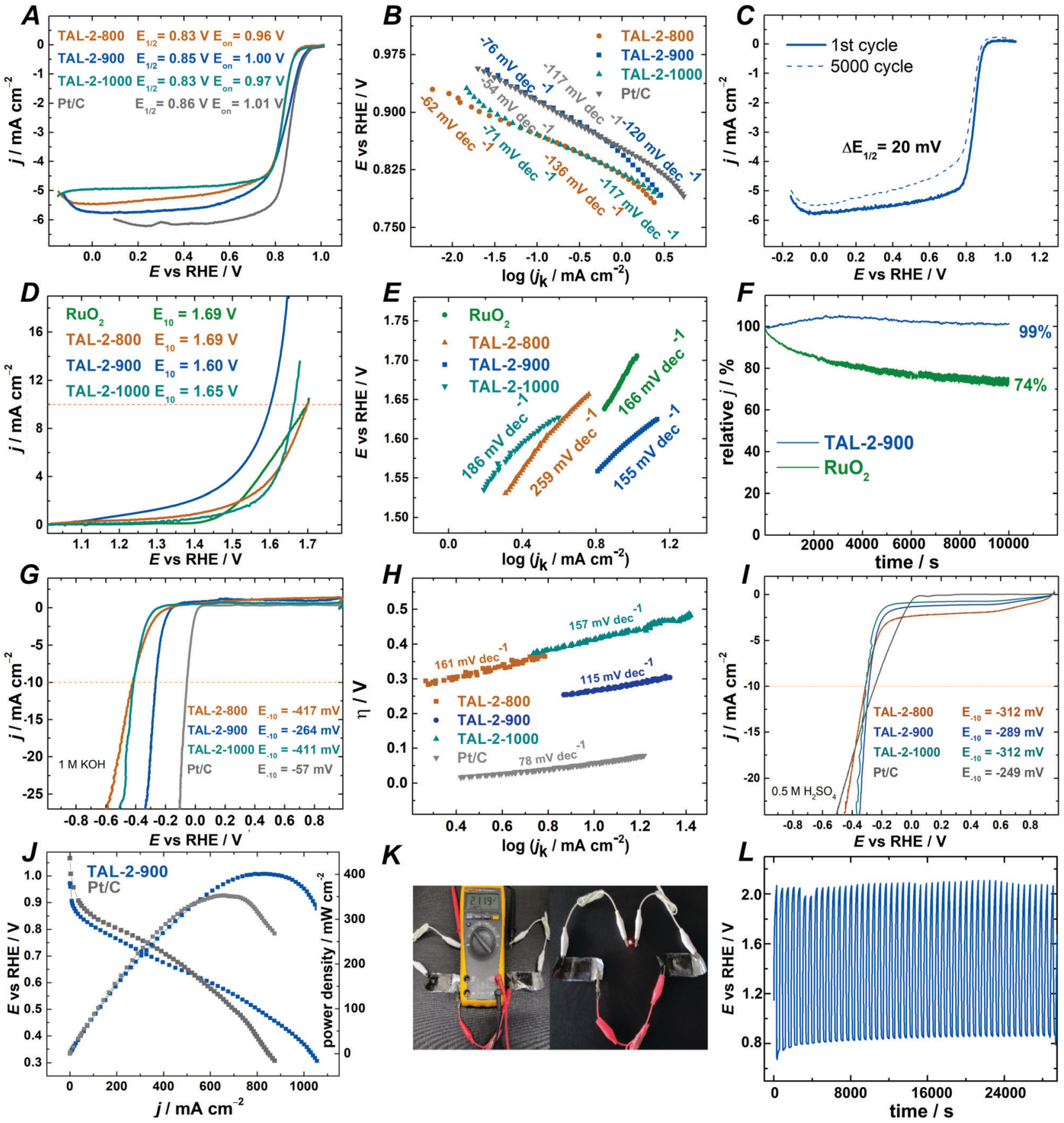

Fig. 3 Electrochemical characterization of TAL-2 derived catalyst materials. (A) ORR polarization curves for TAL and Pt/C-modified GC electrodes at $1600 \mathrm{rpm} ; \nu=10 \mathrm{mV} \mathrm{s}^{-1}$. (B) Tafel plots for ORR on TAL and Pt/C catalysts. (C) Electrochemical ORR stability test for TAL-2-900 (mid-range: 0.6-1.0 V). (D) OER polarization curves (under argon); $\nu=10 \mathrm{mV} \mathrm{s}^{-1}$. (E) OER Tafel plots. (F) OER chronoamperometric stability of TAL-2-900 and RuO 2 in $0.1 \mathrm{M} \mathrm{KOH}$ over 10000 seconds (1.6 V). (G) HER polarization curves for TAL and Pt/C electrocatalysts in $1 \mathrm{M} \mathrm{KOH;} \nu=10 \mathrm{mV} \mathrm{s}^{-1}$. (H) HER Tafel plots for TAL and Pt/C electrocatalysts in $1 \mathrm{M} \mathrm{KOH}$. (I) HER polarization curves for TAL and Pt/C electrocatalysts in $0.5 \mathrm{M} \mathrm{H}_{2} \mathrm{SO}_{4} ; \nu=10 \mathrm{mV} \mathrm{s}^{-1}$. (J) Alkaline single fuel cell test of TAL-2-900 and Pt/C. (K) Zinc-air battery testing with TAL-2-900, shows the voltage produced by two batteries, LED light using the same batteries, and (L) galvanostatic cycling of one battery for $8 \mathrm{~h}$.

and TAL-2-1000 were 417 and $411 \mathrm{mV}$, respectively, indicating that the carbonization step at $900{ }^{\circ} \mathrm{C}$ was the optimal path to improve the electroactivity toward HER. In acidic media, the overpotential $(\eta)$ was the smallest for TAL-2-900, while its overpotential was comparable to the values obtained for other Pt-free HER catalysts (Fig. 3I and Table S9, ESI†).
Finally, the performance of TAL-2-900 as catalyst material was evaluated in alkaline electrolyte membrane fuel cell and zinc-air battery. Alkaline membrane fuel cell test yielded current density up to $1100 \mathrm{~mA} \mathrm{~cm} \mathrm{~cm}^{-2}$ (Fig. 3J). Loading of the catalyst was kept at $2 \mathrm{mg} \mathrm{cm}^{-2}$ on GDL membrane modified with direct suspension pipetting. HMT-PMBI (hydroxide 
conducting membrane) was used as polymer electrolyte in both tests for Pt/C and TAL-2-900. Under similar conditions, TAL-2900 showed $20 \%$ better activity than $\mathrm{Pt} / \mathrm{C}$. The value of power density for TAL-2-900 is $>400 \mathrm{~mW} \mathrm{~cm}^{-2}$ leaving behind $\mathrm{Pt} / \mathrm{C}$ $350 \mathrm{~mW} \mathrm{~cm}^{-2}$. Similar results were recently reported using the same anion exchange membrane and an alternative $\mathrm{Co}-\mathrm{N}-\mathrm{C}$ material as a cathode catalyst. ${ }^{53}$ Durability tests of poly(vinyl alcohol)-based solid-state zinc-air battery assembled using TAL-2-900 as an electrode material were performed by cycling at constant current density of $5.0 \mathrm{~mA} \mathrm{~cm} \mathrm{~cm}^{-2}$ (Fig. 3K). As expected from the ORR/OER data, TAL-2-900 catalyst-driven Zn-air battery delivered long cycle life over 8 h (Fig. 3L).

\section{Conclusions}

In conclusion, we have introduced a new materials preparation strategy by involving amorphous not crystalline MOFs, which were obtained from dihydroxybenzimidazole as a carbonaceous linker. Upon carbonization, it delivered a unique $\mathrm{Co}-\mathrm{N}-\mathrm{C}$ material, which simultaneously served as a heterogeneous catalyst for several organic transformations (incl. oxidation and homocoupling reactions) as well as an electrocatalyst material for ORR, OER and HER processes. This is the first example of an $\mathrm{M}-\mathrm{N}-\mathrm{C}$ catalyst being used for $\mathrm{C}\left(\mathrm{sp}^{3}\right)-\mathrm{C}\left(\mathrm{sp}^{3}\right)$ carbon-carbon bond formation, and it was carried out in the presence of an organometallic reagent.

\section{Author contributions}

Kefeng Ping, Mahboob Alam: investigation, methodology, formal analysis, validation, writing - original draft; writing review and editing; Sean Ray Kahnert, Rohit Bhadoria, Arvo Mere, Valdek Mikli, Maike Käärik, Jaan Aruväli, Päärn Paiste, Arvo Kikas, Vambola Kisand, Ivar Järving, Jaan Leis: investigation, methodology, formal analysis, writing - review and editing; Nadežda Kongi, Pavel Starkov: conceptualization, supervision, writing - original draft, writing - review and editing, funding acquisition.

\section{Conflicts of interest}

K. P., N. K. and P. S. are inventors on the PCT Appl. filed by the University of Tartu and Tallinn University of Technology.

\section{Acknowledgements}

This research was supported by Estonian Research Council (PSG250 and PUT1290) and TalTech Young Investigator Grant B62. We thank Prof. Steven Holdcroft (Simon Fraser University) for providing the HMT-PMBI membrane. The measurement facilities were supported by Institutional Research Grants IUT34-14 and TK141 (Advanced materials and hightechnology devices for energy recuperation systems). K. P. acknowledges Estonian Smart Specialization PhD Fellowship.
P. S. thanks COST Action CA18224 members (https://greener ing.eu) for fruitful discussions.

\section{Notes and references}

1 Z. W. Seh, J. Kibsgaard, C. F. Dickens, I. Chorkendorff, J. K. Nørskov and T. F. Jaramillo, Science, 2017, 355, eaad4998.

2 J. Masa, C. Andronescu and W. Schuhmann, Angew. Chem., Int. Ed., 2020, 59, 15298-15312.

3 A. Sarapuu, E. Kibena-Põldsepp, M. Borghei and K. Tammeveski, J. Mater. Chem. A, 2018, 6, 776-804.

4 L. He, F. Weniger, H. Neumann and M. Beller, Angew. Chem., Int. Ed., 2016, 55, 12582-12594.

5 L. Liu and A. Corma, Chem. Rev., 2018, 118, 4981-5079.

6 M. B. Gawande, P. Fornasiero and R. Zbořil, ACS Catal., 2020, 10, 2231-2259.

7 H. B. Wu and X. W. Lou, Sci. Adv., 2017, 3, eaap9252.

8 P.-Q. Liao, J.-Q. Shen and J.-P. Zhang, Coord. Chem. Rev., 2018, 373, 22-48.

9 H. Yan, C. Su and J. He, J. Mater. Chem. A, 2018, 6, 8793-8814.

10 S. Mitchell, E. Vorobyeva and J. Pérez-Ramírez, Angew. Chem., Int. Ed., 2018, 57, 15316-15329.

11 H.-F. Wang, L. Chen, H. Pang, S. Kaskel and Q. Xu, Chem. Soc. Rev., 2020, 49, 1414-1448.

12 X. F. Lu, B. Y. Xia, S.-Q. Zang and X. W. Lou, Angew. Chem., Int. Ed., 2020, 59, 4634-4650.

13 E. M. Miner, L. Wang and M. Dincă, Chem. Sci., 2018, 9, 6286-6291.

14 H. Zhong, K. H. Ly, M. Wang, Y. Krupskaya, X. Han, J. Zhang, J. Zhang, V. Kataev, B. Büchner, I. M. Weidinger, S. Kaskel, P. Liu, M. Chen, R. Dong and X. Feng, Angew. Chem., Int. Ed., 2019, 58, 10677-10682.

15 S. S. Shinde, C. H. Lee, J.-Y. Jung, N. K. Wagh, S.-H. Kim, D.-H. Kim, C. Lin, S. U. Lee and J.-H. Lee, Energy Environ. Sci., 2019, 12, 727-738.

16 M. Aygün, T. W. Chamberlain, M. C. Gimenez-Lopez and A. N. Khlobystov, Adv. Funct. Mater., 2018, 28, 1802869.

17 X.-J. Bai, X.-Y. Lu, R. Ju, H. Chen, L. Shao, X. Zhai, Y.-N. Li, F.-Q. Fan, Y. Fu and W. Qi, Angew. Chem., Int. Ed., 2021, 60, 701-705.

18 S. L. Zhang, B. Y. Guan and X. W. Lou, Small, 2019, 15, 1805324.

19 X. P. Han, X. F. Ling, Y. Wang, T. Y. Ma, C. Zhong, W. B. Hu and Y. D. Deng, Angew. Chem., Int. Ed., 2019, 58, 5359-5364.

20 T. D. Bennett and A. K. Cheetham, Acc. Chem. Res., 2014, 47(5), 1555-1562.

21 T. D. Bennett and S. Horike, Nat. Rev. Mater., 2018, 3, 431-440.

22 K. Ping, A. Braschinsky, M. Alam, R. Bhadoria, V. Mikli, A. Mere, J. Aruväli, P. Paiste, S. Vlassov, M. Kook, M. Rähn, V. Sammelselg, K. Tammeveski, N. Kongi and P. Starkov, ACS Appl. Energy Mater., 2020, 3, 152-157.

23 K. Ping, M. Alam, M. Käärik, J. Leis, N. Kongi, I. Järving and P. Starkov, Synlett, 2019, 1536-1540. 
24 D. Kong, Y. Gao, Z. Xiao, X. Xu, X. Li and L. Zhi, Adv. Mater., 2019, 31, 201804973.

25 S. Li, X. Hao, A. Abudula and G. Guan, J. Mater. Chem. A, 2019, 7, 18674-18707.

26 W. Zhang, L. Cui and J. Liu, J. Alloys Compd., 2020, 821, 153542.

27 W. Liu, L. Zhang, X. Liu, X. Liu, X. Yang, S. Miao, W. Wang, A. Wang and T. Zhang, J. Am. Chem. Soc., 2017, 139, 10790-10798.

28 T. Song, Z. Ma, Y. Yuan, J. Xiao, Y. Yang and P. Ren, ACS Catal., 2020, 10, 4617-4629.

29 M. Nakanishi and C. Bolm, Adv. Synth. Catal., 2007, 349, 861-864.

30 Y. Li, S. Jie, K. Li and Z. Liu, New J. Chem., 2018, 42, 12677-12683.

31 P. Zhou, L. Jiang, F. Wang, K. Deng, K. Lv and Z. Zhang, Sci. $A d v ., 2017$, 3, e1601945.

32 S. Yang, L. Peng, D. T. Sun, E. Oveisi, S. Bulut and W. L. Queen, ChemSusChem, 2018, 11, 3131-3138.

33 F. Chen, A. Surkus, L. He, M. Pohl, J. Radnik, C. Topf, K. Junge and M. Beller, J. Am. Chem. Soc., 2015, 137, 11718-11724.

34 F. Chen, C. Kreyenschulte, J. Radnik, H. Lund, A. Surkus, K. Junge and M. Beller, ACS Catal., 2017, 7, 1526-1532.

35 R. V. Jagadeesh, K. Murugesan, A. S. Alshammari, H. Neumann, M. M. Pohl, J. Radnik and M. Beller, Science, 2017, 358, 326-332.

36 R. Xie, F. Xie, C. J. Zhou, H. F. Jiang and M. Zhang, J. Catal., 2019, 377, 449-454.

37 F. Xie, R. Xie, J. X. Zhang, H. F. Jiang, L. Du and M. Zhang, ACS Catal., 2017, 7, 4780-4785.

38 H. Luo, L. Wang, S. Shang, G. Li, Y. Lv, S. Gao and W. Dai, Angew. Chem., Int. Ed., 2020, 59, 19268-19274.
39 Y. Zhou, Y. Chen, L. Cao, J. Lu and H. Jiang, Chem. Commun., 2015, 151, 8292-8295.

40 W. Zhong, H. Liu, C. Bai, S. Liao and Y. Li, ACS Catal., 2015, 5, 1850-1856.

41 L. Zhang, A. Wang, W. Wang, Y. Huang, X. Liu, S. Miao, J. Liu and T. Zhang, ACS Catal., 2015, 5, 6563-6572.

42 F. Xie, R. Xie, J. X. Zhang, H. F. Jiang, L. Du and M. Zhang, ACS Catal., 2017, 7, 4780-4785.

43 R. Xie, F. Xie, C. J. Zhou, H. F. Jiang and M. Zhang, J. Catal., 2019, 377, 449-454.

44 H. Gilman and R. G. Gorsich, J. Am. Chem. Soc., 1955, 77, 3134-3135.

45 R. A. Aitken, P. K. G. Hodgson, J. J. Morrison and A. O. J. Oyewale, J. Chem. Soc., Perkin Trans. 1, 2002, 3, 402-415.

46 F. O. Ginah, T. A. Donovan Jr., S. D. Suchan, D. R. Pfennig and G. W. Ebert, J. Org. Chem., 1990, 55, 584-589.

47 S.-i. Inaba, H. Matsumoto and R. D. Rieke, Tetrahedron Lett., 1982, 23, 4215-4216.

48 K. Sato, Y. Inoue, T. Mori, A. Sakaue, A. Tarui, M. Omote, I. Kumadaki and A. Ando, Org. Lett., 2014, 16, 3756-3759.

49 V. V. Levin, D. P. Agababyan, M. I. Struchkova and A. D. Dilman, Synthesis, 2018, 2930-2935.

50 G. Park, S. Y. Yi, J. Jung, E. J. Cho and Y. You, Chem. - Eur. J., 2016, 22, 17790-17799.

51 R. Paul, F. Du, L. Dai, Y. Ding, Z. L. Wang, F. Wei and A. Roy, Adv. Mater., 2019, 31, 1805598.

52 S. Ghosh and R. N. Basu, Nanoscale, 2018, 10, 11241-11280.

53 J. Lilloja, E. Kibena-Põldsepp, A. Sarapuu, M. Kodali, Y. Chen, T. Asset, M. Käärik, M. Merisalu, P. Paiste, J. Aruväli, A. Treshchalov, M. Rähn, J. Leis, V. Sammelselg, S. Holdcroft, P. Atanassov and K. Tammeveski, ACS Appl. Energy Mater., 2020, 3, 5375-5384. 